Cite as: Brune, M., Eiroa-Orosa, F. J., Fischer-Ortman, J., \& Haasen, C. (2014). Effectiveness of psychotherapy for traumatized refugees without a secure residency status. International Journal of Migration, Health and Social Care, 10(1), 52-59. http://doi.org/10.1108/IJMHSC-07-2013-0022

\title{
Effectiveness of psychotherapy for traumatized refugees without a secure residency status
}

Michael Brune, Francisco Jose Eiroa-Orosa, Julia Fischer-Ortman and Christian Haasen

\begin{abstract}
Psychotherapy with refugees in the western world is quite often complicated because many refugees live under high stress caused by the lack of a secure residency status. It is difficult to have a structured therapeutic perspective when doing psychotherapy with these patients because of patient's fears and daily problems. This study evaluated psychotherapy results for 190 traumatized refugees, (40\% without a secure residency). The study shows that although refugees without a legal status had more depressive symptoms and lived with much higher psychosocial stress, psychotherapy was as effective as with traumatized refugees with a legal status.
\end{abstract}

\section{Key words}

Traumatized refugees, Psychotherapy, Legal residency, Legal status, Psychosocial stress

Dr Michael Brune is a Psychiatrist, based at Psychotherapy and Intercultural Communication, Hamburg, Germany.

Dr Francisco Jose Eiroa-Orosa is a Lecturer in Psychology, based at the University of East London, London, UK.

Dr Julia Fischer-Ortman is a Psychologist, based at Haveno, Psychotherapy and Intercultural Communication, Hamburg, Germany.

Professor Christian Haasen is a Psychiatrist, based at Altomed- MVZ, Hamburg, Germany 


\section{Structured Abstract}

Purpose: Psychotherapy with refugees in the western world is quite often complicated because many refugees live without a secure residency status. It is difficult to have a structured therapeutic perspective when doing psychotherapy with these patients because of their fears and daily problems. This study evaluated psychotherapy results for 190 traumatized refugees, (40\% without a secure residency).

Design: To measure the outcome of the psychotherapies we used HAM-D and CGI at baseline and at the end of the therapeutic process.

Findings: The study shows that, although refugees without a legal status had more depressive symptoms and lived with much higher psychosocial stress, psychotherapy was as effective as for traumatized refugees with a legal status.

Research limitations: Heterogeneity, convenience sampling and retrospective completion of some of the baseline assessments.

Practical implications: Psychotherapeutic treatment of refugees has a clear positive effect on them and should be applied even in those without legal residence status in the host country.

Social implications: Offering mental health care and psychotherapy to traumatized refugees, makes sense independently of their legal status and the difficulties associated.

Originality/value: This is the first study assessing the effectiveness of daily practice psychotherapy for refugees with and without a legal status in a comparative fashion. 


\section{Introduction}

People flee from their countries for different reasons. Some do it because they have been victims of political violence, as political persecution, torture, wars or other armed conflicts. Many of these victimized persons have experienced one or several traumatic events before or during their flight from their country of origin and their mental health is affected by these events. In the context of this article, we refer to these persons as traumatized refugees (Mollica, Wyshak, \& Lavelle, 1987). The frequency and severity of the sufferings of refugees is quite often underestimated in the western countries (Weaver \& Burns, 2001). Among traumatized refugees seeking psychotherapeutic help in this context, many suffer under high psychosocial stress by not having a secure legal residence in the country where they have sought shelter. They are either still in the asylum process or already have been denied asylum, but because of some practical problems they cannot be expulsed at the moment, or in some cases their stay in the country is simply illegal ('undocumented' or 'paperless' persons).

These refugees live with permanent risk of being obliged to leave the country or even be deported despite incompliance of human rights (Fekete, 2005). Their situation means that they are lacking the possibility to plan their near future and structure their daily life. In the country of exile, they live from one day to another. Furthermore, nearly all of them are convinced that leaving the country of exile would mean a severe worsening of their situation. Most of them see this as a threat of an upcoming catastrophe and some are convinced that a deportation would lead them to new imprisonment, torture or even death. These difficult and stressing living conditions raise the risk of developing mental disorders (Lears \& Abbott, 2005; Mueller, Schmidt, Staeheli, \& Maier, 2011). In addition comes the fact that most of them are psychologically affected coping with the feeling that they have not been taken seriously when reporting the political persecution they have suffered when seeking asylum. Due to this tense and unstable situation many of these traumatized refugees live with a high 
level of psychosocial stress, which affects them mentally and complicates the goals of psychotherapy.

It has been questioned if it makes sense to offer psychotherapy to traumatized persons without a secure legal status. Some experts believe that it only makes sense to give social support while persons are waiting to legalize permanently their stay in the country of exile. In consequence some treatment centres for torture victims in the western world only offer help to refugees with a permanent residency in the country of exile (e. g. Red Cross Center for Tortured Refugees, 2011). Nonetheless, there are many professionals who try to give psychotherapeutic help to traumatized persons, even though they have an unsure legal status and hence an unstable social situation. Furthermore, there are studies (Brune et al., 2002; Procter, 2005; Renner, 2009; Weine, Kulenovic, Pavkovic, \& Gibbons, 1998) showing that psychotherapy with refugees and asylums seekers can be effective. These experts believe that the main criteria to give psychotherapy to this group should be the same as for any other traumatized person: the patient's clinical symptoms and his psychological suffering.

Difficulties in the therapy with traumatised refugees without a legal status in the country of exile have also to do with the general problem of giving medical, psychiatric and psychotherapeutic care to persons living 'illegally', which yet is a major socio-medical problem in the European Union.

\section{Psychotherapy with traumatized refugees}

Psychotherapy with traumatized refugees and other persons, who have been victims of political violence, requires a modified approach towards the patient. A strict application of the concept of posttraumatic stress disorder (PTSD) is not possible because of etiological and cultural reasons (Becker, 1995; Bracken, Giller, \& Summerfield, 1995). Cultural, religious, historical, political and existential aspects of the traumatization must be elaborated, as well 
for the understanding of the patient, as an instrument in the psychotherapy (Brune, EiroaOrosa, Fischer-Ortman, Delijaj, \& Haasen, 2011; Brune, et al., 2002).

Psychotherapy with traumatized refugees without a secure legal status in the country of exile has to consider the same aspects as when working with refugees that already have a secure status. However, in other respects there are differences. For instance, in every day clinical management with persons without secure legal residency clinicians usually play a more psychoeducative role. Furthermore, these psychotherapies also have more phases similar to crisis interventions, in which the main aim of therapy is not to elaborate traumatic experiences or inner conflicts, but to stabilize the patient, avoiding acute crises. Working with persons without a secure legal status forces the psychotherapist to often act outside the therapeutic room, repeatedly the circumstances take him/her to the limits of his/her concept of his/her professional role. There are often many professionals, as lawyers, social workers and members of non-governmental organisations helping refugees, who ask verbal or written information from the psychotherapist about the patient, mainly about legal and social questions. As this required information is for the benefit of the patient, the psychotherapist is often asked to give practical help to patients lacking a secure residence (Tribe, 2002).

\section{Psychotherapist's stress regarding not legalized patients}

Patient's psychosocial stress can be projected on the psychotherapist (Birck, 2001). It is easy to begin to share the fears, frustration and anger of the patients, which often are extremely disappointed about how they have been treated in the country of exile, to which they once had come with high expectations. The psychotherapist can never be sure that the therapy will go on as planned. There is always a real risk of deportation of his/her patient, which means that any session could be the last one, which is difficult to handle in a proper way. On the other hand it is also often hard to end the psychotherapies as once planned, e.g. after a certain number of sessions and/or when the psychological goals of the therapy have 
been reached. As long as the legal process regarding the possible residency is still ongoing, the patient will be in great need of supportive psychosocial help and often asks the psychotherapist to go on with psychotherapy, as he/she is the only person of confidence. For the psychotherapist, it is hard to reject such a request. Furthermore, the issue of financing therapy sessions becomes a larger problem, as social and health insurances nearly never pay more than a certain number of sessions and the patients usually have no economic resources.

The aim of this study is to analyze if psychotherapy with traumatized refugees without a secure legal status can be as effective and if there are differences in baseline characteristics and psychotherapy outcome when compared with traumatized refugees with a secure legal status. Furthermore, we wanted to analyse the specific weight of the legal status over other variables.

\section{Method}

\section{Sample.}

A total of 190 patients were included in the present study. Data on 141 of them have been used in a study about the role of belief systems in traumatized refugees (Brune, et al., 2002). The other 49 were prospectively analysed and also used in a replication study (EiroaOrosa, Brune, Huter, Fischer-Ortman, \& Haasen, 2011). Both studies used a similar design and had instruments in common so analyses about the efficacy of interpreters in psychotherapy (Brune, et al., 2011) and the present analysis could be carried out. All patients had had traumatic experiences, these playing an important part in the genesis of their mental disorders. All of them had experienced organized violence in their countries of origin (torture, imprisonment, war and other forms of persecution), and then sought refuge in Sweden or Germany. The main regions of origin were Iran (58), Ex-Yugoslavia (27), Latin America (26), Turkey (21), Africa (16), Iraq (15) and Russia (18). Eighteen patients came from other 
countries (Afghanistan, Albania, Azerbaijan, Bangladesh, Bulgaria, Lebanon, Palestine, Syria and Syrian Kurdistan).

For the present study, we divided the patients into two groups, one group with those who had a legal residency (121 persons, 63.7\%) and the other composed of those who had no secure legal status (69 persons, 37.3\%) at the beginning of treatment.

\section{Therapeutic approach.}

All patients were treated with psychotherapy. The psychotherapies included psychodynamic, cognitive and supportive psychotherapeutic approaches using a therapeutic program as defined by Van Der Veer (1992) and Basoglu (1992). Cultural influences in treatment response were taken into consideration suiting treatment approaches as outlined by Morris and Silove (1992). In the study there were four psychotherapists involved, whose experience working in psychotherapy with traumatized persons ranged from three to ten years at the beginning of this study. Some of the patients $(36.3 \%)$ also received different psychopharmacological treatments, mainly antidepressive, anxiolytic and hypnotic medication. The average duration of the therapies was 22.05 months (S.D. $=14.70$, range 372).

\section{Measures.}

To measure the outcome of the psychotherapies we used HAM-D (Hamilton, 1967) and CGI (National Institute of Mental Health, 1970). As all the included persons in this sample were traumatized refugees, they all were confronted with severe losses, which in turn lead to reactive depressive symptoms in all of them. Therefore we believe that the combination of these two instruments is a sufficient measure for the aim of this study.

In this study we defined psychosocial stress as the existence of one or more circumstances in the person's actual living conditions that permanently kept him or her worried and preoccupied, and subjectively gave him/her the feeling of being put under stress. 
We defined four different categories of psychosocial stress, going from no psychosocial stress until extreme psychosocial stress. We made an evaluation of the psychosocial stress at the beginning and at the end of the therapy.

\section{Results}

\section{Sample characteristics.}

Table 1 shows sociodemographic and treatment characteristics by residence status. 135 patients $(71.1 \%)$ were men and $55(28.9 \%)$ women. The mean age of the patients was 35.93 (range 15-68, S.D.=9.151). $121(63.7 \%)$ had a secure residence status, $123(64.7 \%)$ stable housing, $61(32.1 \%)$ were employed or had a stable benefit due to disabilities and $72(37.9 \%)$ had completed a vocational training (university or professional education). Significant differences were found in four characteristics. In the group without residency a greater proportion were women, less had stable housing, less were employed, the expectations on the country of asylum were less fulfilled and had more than twice psychosocial stress.

Table 1. Distribution of those treated with and without interpreters by countries of origin.

\begin{tabular}{|c|c|c|c|}
\hline & $\begin{array}{l}\text { Insecure Residence } \\
(n=69)\end{array}$ & $\begin{array}{l}\text { Secure } \\
(\mathrm{n}=121)\end{array}$ & Total $(n=190)$ \\
\hline Iran & 7 & 51 & 58 \\
\hline Ex-Yugoslavia & 15 & 12 & 27 \\
\hline Latin America & 11 & 15 & 26 \\
\hline Turkey & 10 & 11 & 21 \\
\hline Africa & 8 & 8 & 16 \\
\hline Iraq & 1 & 14 & 15 \\
\hline Russia & 9 & 0 & 9 \\
\hline Other countries & 8 & 10 & 18 \\
\hline
\end{tabular}

Others include: Afghanistan, Albania, Azerbaijan, Bangladesh, Bulgaria (Turkish origin), Lebanon, Palestine, Syria and Syrian Kurdistan. 
More than two thirds of the patients were diagnosed with PTSD. A more detailed diagnostic description of the sample can be seen elsewhere (Brune, et al., 2011). We have also compared the times and length of traumatization, finding that those without legal residence status had been more often in prison $(\mathrm{t}=2.001, \mathrm{p}<.05)$, while those with legal status had been in prison longer $(\mathrm{t}=2.877, \mathrm{p}<.01)$ and tortured more often $(\mathrm{t}=2.014, \mathrm{p}<.05)$.

The average HAM-D score for all patients at the beginning of the treatment was 16.54 (range 6-45, S.D.=6.07) and 8.06 at the end (range 0-27, S.D.= 5.06). The average reduction was 8.47 (range $-6-28$, S.D.=5.33), which corresponds to a $50.76 \%$ reduction. CGI ranged from 3 to 6 at the beginning of the therapies (mean=5.32, S.D.=6.40) and from 1 to 6 at the end (mean=2.65, S.D.=1.25). The average reduction was 2.67 (range 0-5, S.D.=1.34), 24.02\%. Both reductions had a high correlation $(\mathrm{r}=.53, \mathrm{p}<.0001)$. Psychosocial stress average score was 1.16 at the beginning (range $0-3, \mathrm{~S} . \mathrm{D}=1.054$ ) and .86 at the end of the study (range range $0-3, \mathrm{~S} . \mathrm{D}=1.016)$.

Initial HAMD initial score showed a significant difference between groups, with higher score in the group without residency, and a slightly significant higher score in the final HAMD. Considering the CGI, scores in the t-test showed no significant differences, not in the beginning nor at the end of psychotherapy. Psychosocial stress scores were higher in the group without legal status both at the beginning and end of the therapy. Repeated measures analyses of variance (RM ANOVA) were carried out to check time effect and compare between insecure and secure residence groups. Time effect was found significant for the three measures and group interaction effect was found significant only in HAMD showing a higher decrease in the secure residence group. Initial and end scores and statistical signification of comparisons between groups can be seen in table 2 . 
Table 2. Sociodemographic characteristics of the sample at baseline.

\begin{tabular}{|c|c|c|c|c|c|}
\hline & \multicolumn{2}{|c|}{$\begin{array}{l}\text { Insecure Residence } \\
\qquad(\mathrm{n}=69)\end{array}$} & \multicolumn{2}{|c|}{$\begin{array}{l}\text { Secure Residence } \\
\qquad(\mathrm{n}=121)\end{array}$} & \multirow[t]{2}{*}{ Significance } \\
\hline & $\mathrm{M}$ & SD & $\mathrm{M}$ & SD & \\
\hline Age at beginning of treatment (Mean/ SD) & 34.91 & 9.92 & 36.51 & 8.67 & $\mathrm{t}=1.160, \mathrm{p}=.248$ \\
\hline $\begin{array}{l}\text { Foreign language proficiency in a range from } \\
\qquad 1 \text { to } 5 \text { (Mean/ SD) }\end{array}$ & 2.78 & 0.95 & 2.82 & 1.06 & $\mathrm{t}=-.230, \mathrm{p}=.818$ \\
\hline Duration of treatment in months (Mean/ SD) & 20.32 & 10.89 & 23.03 & 16.44 & $\mathrm{t}=1.365, \mathrm{p}=.174$ \\
\hline $\begin{array}{l}\text { Years in asylum country at the beginning of } \\
\text { therapy }\end{array}$ & 3.46 & 2.72 & 4.12 & 4.67 & $\mathrm{t}=1.243, \mathrm{p}=.281$ \\
\hline $\begin{array}{l}\text { Fulfilled expectations in the country of } \\
\text { asylum in a range from } 1 \text { to } 4\end{array}$ & 1.75 & 0.65 & 2.35 & 0.63 & $\begin{array}{l}t=6.178 \\
p<.0001\end{array}$ \\
\hline & $\mathrm{N}$ & $\%$ & $\mathrm{~N}$ & $\%$ & \\
\hline Female gender $(\mathrm{n} / \%)$ & 26 & 37.7 & 29 & 24.0 & $\begin{array}{c}\chi^{2}=4.018 \\
p=.045\end{array}$ \\
\hline Living with partner (n/\%) & 37 & 54.4 & 48 & 41.4 & $\chi^{2}=.372 ., p=.542$ \\
\hline Stable housing $(\mathrm{n} / \%)$ & 30 & 43.5 & 93 & 76.9 & $\begin{array}{c}\chi^{2}=21.499 \\
p<.0001\end{array}$ \\
\hline Employed (n/\%) & 15 & 21.7 & 46 & 38.0 & $\begin{array}{c}\chi^{2}=5.341 \\
p<.021\end{array}$ \\
\hline Completed vocational training $(\mathrm{n} / \%)$ & 26 & 37.7 & 46 & 38.0 & $\chi^{2}=.002, p=.963$ \\
\hline Good social network (n/\%) & 43 & 62.3 & 71 & 58.7 & $\chi^{2}=.243, p=.622$ \\
\hline Use of interpreter during therapy $(\mathrm{n} / \%)$ & 31 & 44.9 & 62 & 51.2 & $\chi^{2}=.701, p=.403$ \\
\hline Use of pharmacs during therapy $(\mathrm{n} / \%)$ & 27 & 39.1 & 42 & 34.7 & $\chi^{2}=.371, p=.542$ \\
\hline
\end{tabular}

Finally, linear stepwise regressions were used in order to select the more relevant variables influencing amelioration of symptoms. Results can be seen in table 3. HAM-D amelioration was predicted by secure residence status and use of medication, CGI by completed education and social network and psychosocial stress by the use of medication. 
Table 3. Therapy outcome measured by reduction of CGI and HAM-D scores (mean \pm SD) by stress groups.

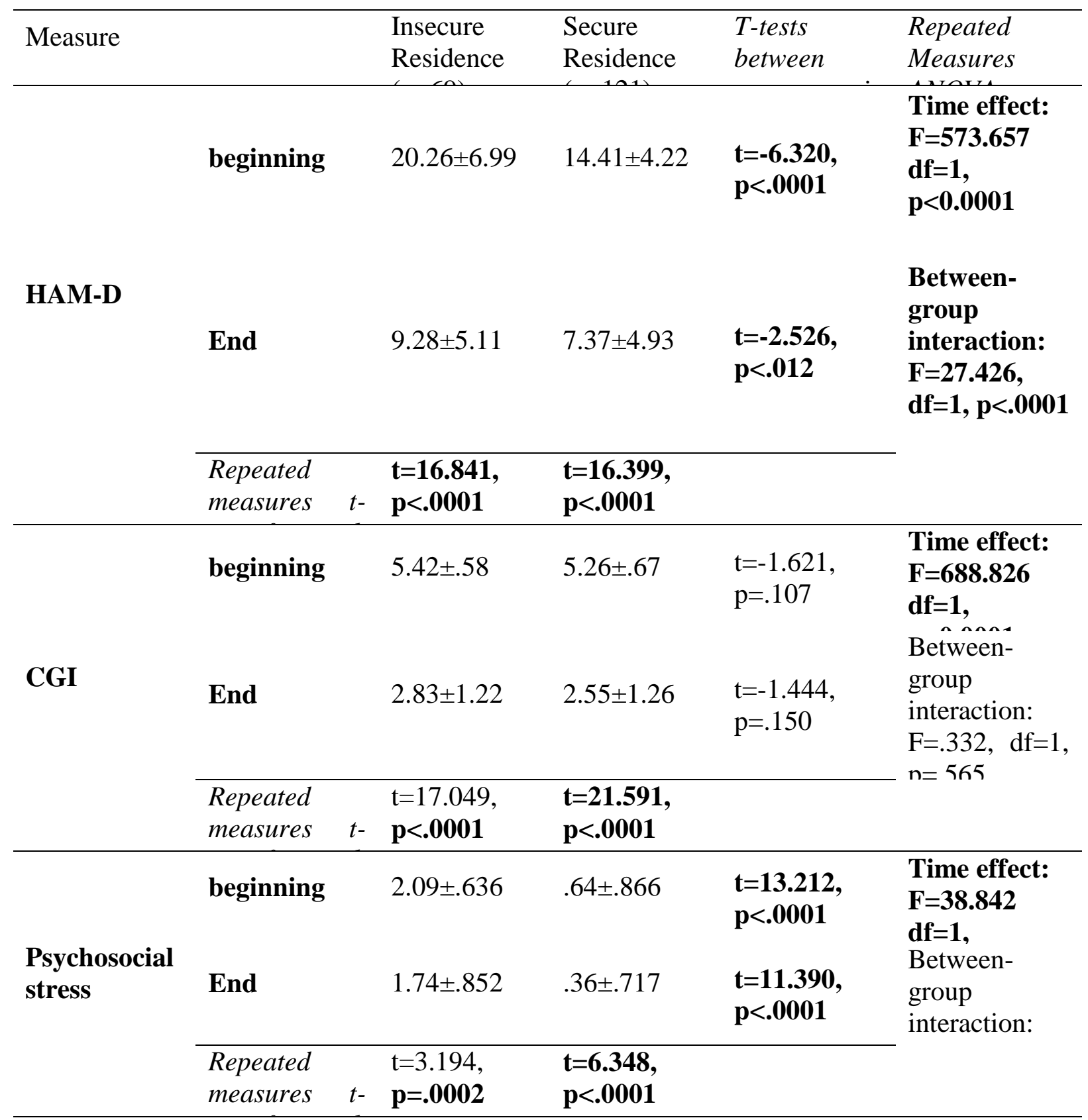


Table 4. Linear stepwise regressions using as dependent variables HAMD, CGI and psychosocial stress amelioration scores*.

\begin{tabular}{lclcl}
\hline Dependent variable & $\mathbf{R 2}$ & Variables remaining in the final models & $\boldsymbol{\beta}$ & $\mathbf{p}$ \\
\hline HAMD & .16 & Secure residence status & -.357 & $<.0001$ \\
& & Use of medication & .188 & .006 \\
\hline CGI & .071 & Completed education & .191 & .009 \\
\hline \multirow{2}{*}{ Psychosocial stress } & .028 & Social Network & -.160 & .028 \\
\hline
\end{tabular}

*Score at the end of treatment minus score at admission.

(Independent Variables used: gender, age, living with partner, stable housing, employment, completed vocational training (education), social contacts, use of medication and secure residence status).

\section{Discussion}

In this study traumatized refugees, who have no secure residency in the country of exile, have been equally exposed to traumatic experiences by political violence, as those who live with a secure residency. Hence a high degree of traumatization does not automatically lead to a better chance to receive asylum. The consequence, that traumatized refugees without a secure legal status live under far higher stressing psychosocial conditions than those who have a found asylum, can also be seen in this study. Therefore, the stress of not having a legal status comes on top of their suffering due to mental symptoms by traumatization. From a psychiatric and psychological point of view, this indicates that refugees suffering from a traumatization would suffer less, if they would be legalized.

At the beginning of their therapies, traumatized refugees without a legal status had significantly more depressive symptoms than those with a legal status, but at the end of the study this difference between groups was much less pronounced. Interaction between groups showed how patients with an insecure residence had a higher benefit from therapy regarding depressive symptoms. Regarding clinical impression, there were no statistically significant differences at the beginning or at the end of the treatment. In this respect, both had a 
statistically and clinically significant amelioration and no interaction was found with their legal status. With respect to psychosocial stress, patients without a legal status had a significantly higher level both at the beginning and at the end of the therapies. Nevertheless, both groups did improve their scores and, as within clinical impression, no relation was found between amelioration and legal status. The findings indicate that the higher level of depressive symptoms in those traumatized refugees without a secure residency can be explained as reactive depressive symptoms, due to their experiences in the country of exile.

Refugees coming to the West often have idealized thoughts about western countries being highly democratic and having high standards of human rights. When they don't find the security they hoped to find in the country of exile, they feel their human rights are being violated also in the new country, they feel rejected and unprotected everywhere in this world. Furthermore, as many refugees and immigrants, they often underestimate the personal psychosocial and cultural difficulties, which are consequences of living in exile. In addition they generally get much less social, medical and other help and are more marginalized in the new society. This leads to feelings of disappointment, frustration, helplessness, isolation and mistrust. All these feelings are within or similar to depressive symptoms. This is probably why refugees without a secure legal status have a significantly higher degree of depressive symptoms at the beginning of treatment. One explanation for the higher reduction in depressive symptoms in patients without secure residence, would be the fact that they receive help and solidarity from persons in the country of exile, such as the psychotherapist, who as an academic has a good social standing and can do a lot of concrete things, like talking to lawyers, writing reports to authorities etc. This has a high symbolic importance. The patients receive help from an important person, when he/she feels very disappointed, lonely and helpless. The positive emotional transference towards the therapist is generally high. Another explanation would be, that psychotherapy helps to structure a chaotic inner world in persons 
who feel overwhelmed by the difficulties of their realities, and therefore psychotherapy is especially effective. Rational and psychoeducative interventions with explanations about asylum laws, asylum politics and social marginalization of 'paperless' persons are also often helpful. Furthermore, the use of medication in patients with an overall higher score in depressive symptoms (although more heterogeneous at the beginning) was also found to be statistically significant as we think it drove to a homogenization of symptomatology with the rest of the sample, diminishing negativism and other symptoms, and therefore helped in the psychotherapeutic process.

The fact that there are clearly less marked differences between the groups considering the general clinical impression can be explained due to the traumatization suffered before arriving to the new country. Both patients with secure or insecure status were equally traumatized before started psychotherapy. Regarding depressive symptoms, therapy outcome for patients with no secure residency shows to be better than for those who have a secure residence. Although the goodness of fit of the model was very low, we think that the intellectual level and degree of integration helps to understand the unknown situation in the new society leading to a general improvement.

Regarding psychosocial stress, the model yielded also a very low goodness of fit, showing that only the use of medication explained the diminution of these circumstances. This situation can be linked to the amelioration in general depressive symptoms. Limitations of the study must be stressed: the sample was very heterogeneous, PTSD data was not available for the whole sample, and the study was not controlled but rather was made with a sample collected on daily clinical practice with refugees traumatized by organized violence. Finally, the most important finding of the study is that both groups experienced a significant improvement of their symptomatology. Therefore it can definitely be concluded that offering 
psychotherapy to traumatized refugees, makes sense independently of their legal status in the country and the difficulties associated with the lack of a legal status. 


\section{References}

Basoglu, M. (1992). Torture and its Consequences: Current Treatment Approaches. Cambridge: Cambridge University Press.

Becker, D. (1995). The Deficiency of the Concept of Posttraumatic Stress Disorder when Dealing with Victims of Human Rights Violations. In R. J. Kleber, C. R. Figley \& B. P. R. Gersons (Eds.), Beyond trauma: cultural and societal dynamics. New York: Plenum Press.

Birck, A. (2001). Secondary Traumatization and Burnout in Professionals Working with Torture Survivors. Traumatology, 7(2), 85-90. doi: 10.1177/153476560100700203

Bracken, P. J., Giller, J. E., \& Summerfield, D. (1995). Psychological responses to war and atrocity: The limitations of current concepts. Social Science \& Medicine, 40(8), 1073 1082. doi: Doi: 10.1016/0277-9536(94)00181-r

Brune, M., Eiroa-Orosa, F. J., Fischer-Ortman, J., Delijaj, B., \& Haasen, C. (2011). Intermediated communication by interpreters in psychotherapy with traumatized refugees. International Journal of Culture and Mental Health, 4(2), 144-151. doi: $10.1080 / 17542863.2010 .537821$

Brune, M., Haasen, C., Krausz, M., Yagdiran, O., Bustos, E., \& Eisenman, D. (2002). Belief systems as coping factors for traumatized refugees: a pilot study. European psychiatry : the journal of the Association of European Psychiatrists, 17(8), 451-458.

Eiroa-Orosa, F. J., Brune, M., Huter, K., Fischer-Ortman, J., \& Haasen, C. (2011). Belief Systems as Coping Factors in Traumatized Refugees: A Prospective Study. Traumatology, 17(1), 1-7. doi: 10.1177/1534765609358468

Fekete, L. (2005). The deportation machine: Europe, asylum and human rights. Race \& Class, 47(1), 64-78. doi: 10.1177/0306396805055083

Hamilton, M. (1967). Development of a rating scale for primary depressive illness. The British journal of social and clinical psychology, 6(4), 278-296.

Lears, L. O., \& Abbott, J. S. (2005). The most vulnerable among us. Health progress, 86(1), $22-25,60$.

Mollica, R., Wyshak, G., \& Lavelle, J. (1987). The psychosocial impact of war trauma and torture on Southeast Asian refugees. Am J Psychiatry, 144(12), 1567-1572.

Morris, P., \& Silove, D. (1992). Cultural Influences in Psychotherapy With Refugee Survivors of Torture and Trauma. Hosp Community Psychiatry, 43(8), 820-824. 
Mueller, J., Schmidt, M., Staeheli, A., \& Maier, T. (2011). Mental health of failed asylum seekers as compared with pending and temporarily accepted asylum seekers. The European Journal of Public Health, 21(2), 184-189. doi: 10.1093/eurpub/ckq016

National Institute of Mental Health. (1970). CGI: Clinical Global Impressions. In B. R. Guy W (Ed.), Manual for the ECDEU Assessment Battery.2. Rev ed. (pp. 121-126). Bethesda, MD: Chevy Chase.

Procter, N. G. (2005). Providing emergency mental health care to asylum seekers at a time when claims for permanent protection have been rejected. International Journal of Mental Health Nursing, 14(1), 2-6. doi: 10.1111/j.1440-0979.2005.00357.x

Red Cross Center for Tortured Refugees. (2011). Frequently Asked Questions Retrieved 23 August, 2011, from www.redcross.se/rkcstockholm

Renner, W. (2009). The Effectiveness of Psychotherapy with Refugees and Asylum Seekers: Preliminary Results from an Austrian Study. Journal of Immigrant and Minority Health, 11(1), 41-45. doi: 10.1007/s10903-007-9095-1

Tribe, R. (2002). Mental health of refugees and asylum-seekers. Advances in Psychiatric Treatment, 8(4), 240-247. doi: 10.1192/apt.8.4.240

Van de Weerd, M. (1992). Counselling and Therapy with Refugees: Psychological Problems of Victims of War, Torture and Repression. New York: Wiley.

Weaver, H. N., \& Burns, B. J. (2001). 'I Shout with Fear at Night'. Journal of Social Work, l(2), 147-164. doi: 10.1177/146801730100100203

Weine, S. M., Kulenovic, A. D., Pavkovic, I., \& Gibbons, R. (1998). Testimony Psychotherapy in Bosnian Refugees: A Pilot Study. Am J Psychiatry, 155(12), 17201726. 